ONLINE MUTATION REPORT

\title{
Rapp-Hodgkin and AEC syndromes due to a new frameshift mutation in the TP63 gene
}

\author{
I Dianzani, E Garelli, P Gustavsson, A Carando, B Gustafsson, N Dahl, G Annerén
}

J Med Genet 2003;40:e133 (http://www.jmedgenet.com/cgi/content/full/40/12/e133)

listan ncreases in the number of allelic malformation syndromes (due to mutations in a single gene) have led to their classification according to their pathogenesis rather than their clinical specific phenotype. TP63 mutations have been identified in several such syndromes characterised by autosomal dominant transmission and various combinations of ectodermal dysplasia, limb malformations, and orofacial clefting.

The TP63 gene is a TP53 homologue, ${ }^{1-8}$ part of a family composed of only three members. The third member (TP73) is more similar to TP63 than to TP53 in both structure and function. ${ }^{9-13}$ Like p53, p63 has a transactivating (TA), a DNA binding (DB), and a polymerisation domain; it exerts p53like activities in various contexts, such as binding canonical p53 sites, transactivating p53 target genes, and inducing apoptosis. $^{12}$ Unlike TP53, which expresses one major transcript, TP63 contains four separate transcription initiation sites that direct expression of two fundamentally different isotypes that retain (TA products) or lack $(\Delta \mathrm{N}$ products) the TA domain. ${ }^{14}$ Alternative splicing generates additional complexity at the $\mathrm{C}$ terminus.

$\Delta \mathrm{N}$ isoforms lack TA activity and may also suppress the TA isoforms, either by simple competition for the DNA target sites or by acting as dominant negatives through oligomerisation. By contrast to p53, the C terminus in p63 is longer and contains a SAM domain and a TID (transactivation inhibitory domain). SAM domains are involved in protein-protein interactions and probably have regulatory functions in p63, ${ }^{15-17}$ since its TA- $\alpha$ isoform shows a lower TA activity than the $\gamma$ form, which lacks the SAM but retains the TA domain. The TID has been mapped within the $\alpha$ tail downstream to the SAM domain..$^{14}$ The differences at the $\mathrm{C}$ terminus identify three transcripts which have different properties and functions: $\alpha, \beta$, and $\gamma$ isoforms. The $\alpha$ isoforms have the SAM and the TID, and lack the region corresponding to exon 15, which is shown by the $\gamma$ isoforms. The latter are formed by splicing out the regions encoded by exons 11-14. The $\beta$ isoforms lack the region corresponding to exon 13 and use a different frame that finds a stop codon at the beginning of exon 14: they lack both the SAM and the TID. Lastly, p53 is conditionally expressed, whereas p63 is constitutively present. It is expressed mainly in the stem cell compartment of epithelial tissues. $\Delta \mathrm{N}$ products are the most abundant isoforms, and highlight a role for repressive versions in epithelial stem cell identity.

TP63 is rarely mutated in cancer, and its main role is in embryo development. ${ }^{18}{ }^{19}$ In fact, TP63 mutations have been identified in the following malformation syndromes: ectodermal dysplasia, ectrodactyly, cleft lip / palate (EEC: MIM 604292); split-hand / foot malformation (SHFM: MIM 183600); ankyloblepharon-ectodermal dysplasia-cleft (AEC: MIM 106260); limb-mammary syndrome (LM: MIM 603543); and acro-dermato-ungual-lacrimal-tooth syndrome (ADULT: MIM 103285). ${ }^{20-27}$ Patients do not show an increased susceptibility to cancer.

\section{Key points}

- TP63 gene mutations have been identified in several malformation syndromes. An apparently conclusive genotype-phenotype correlation has been deduced from the fact that they are caused by mutations in specific protein domains.

- Our investigation of three multiplex families revealed causal mutations. The family exhibiting Rapp-Hodgkin syndrome (RHS) carried a new mutation, a deletion of an $\mathrm{A}$ located in exon 14 (1859delA).

- This is the first demonstration that RHS is due to a p63 defect. RHS is differentiated from ankyloblepharonectodermal dysplasia-cleft (AEC) syndrome by the absence of ankyloblepharon filiforme adnatum. The finding of this anomaly in one patient from the RHS family suggests that $\mathrm{AEC}$ and RHS are the same clinical entity.

An apparently conclusive genotype-phenotype correlation has been deduced to explain the development of different syndromes (with some exceptions). All but one of the EEC mutations affect the TP63 DNA binding domain, whereas all but one of the AEC mutations are caused by missense mutations affecting the SAM domain. SHFM patients have either missense mutations in the DNA binding domain or nonsense mutations within the $\mathrm{C}$ terminus. Three mutations have been found in LMS patients: two frameshift mutations in exon 13 or 14 , and a missense mutation in exon 4 . ADULT syndrome mutants include one missense mutation in the TA2 domain located at the $\mathrm{N}$ terminal region of the $\Delta \mathrm{N}$ isoform, and a specific missense mutation in the DNA binding domain.

EEC and SHFM missense mutations are expected to lose TA functions; AEC and LMS mutants maintain TA functions, but lose the regulatory functions ascribed to the SAM domain and the TID, respectively. ${ }^{14}{ }^{1728}$ ADULT mutations are mutations that gain function, because they both activate the TA2 domain. These hypotheses have been supported by expression of mutant proteins and analysis of their function in the laboratory or by analogy with p73 and p53 mutants. SHFM is genetically heterogeneous: only $10 \%$ of SHFM are due to TP63.21 24

Rapp-Hodgkin syndrome (RHS: MIM 129400) is autosomal dominant and shares two cardinal symptoms with

\footnotetext{
Abbreviations: TA, transactivation; TID, transactivation inhibitory domain; DB, DNA binding; RHS, Rapp-Hodgkin syndrome; EEC, ectodermal dysplasia, ectrodactyly, cleft lip / palate; SHFM, split-hand / foot malformation; ADULT, acro-dermato-ungual-lacrimal-tooth; AEC, ankyloblepharon-ectodermal dysplasia-cleft; LMS, limb-mammary syndrome; SAM, sterile alpha motif
} 
।

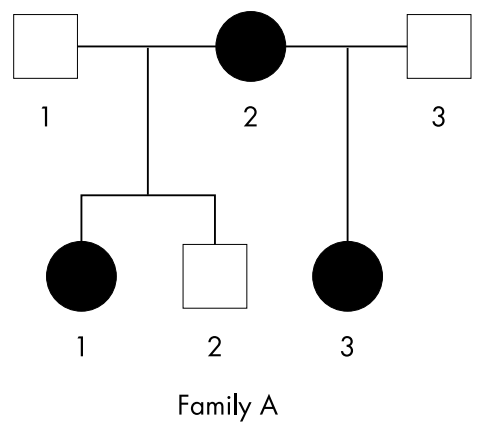

।

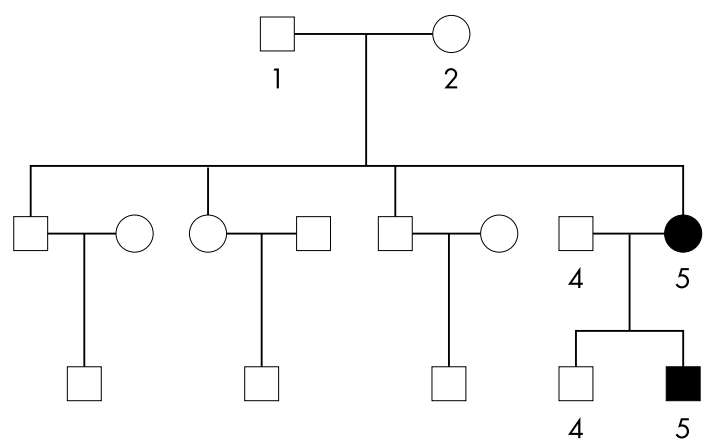

Family B

।

II

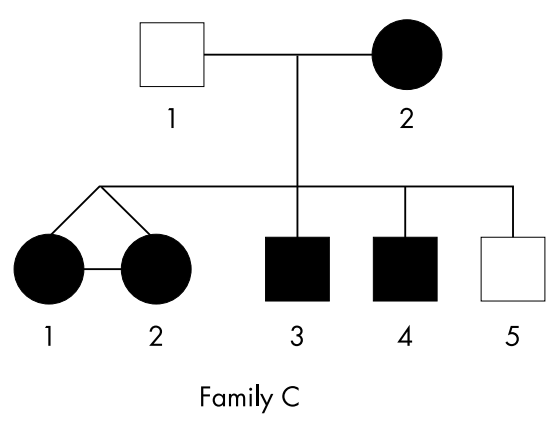

EEC: cleft lip / palate and ectodermal dysplasia. Its other features are hypohidrosis, a peculiar face with a narrow nose and a small mouth, short stature, hypospadias, pili torti or pili canaliculi (uncombable hair), and normal intelligence. ${ }^{29-34}$ The association of hypohidrosis, sparse hair, nail dysplasia, and cleft palate was first described by Rapp and Hodgkin in a mother and her two siblings. ${ }^{35}$ RHS is treated as a syndrome to be ruled out in the diagnosis of EEC, ${ }^{14} 283637$; EEC is sometimes observed unaccompanied by ectrodactyly. ${ }^{38} 39$ However, the birth of a son with EEC to a woman with RHS has suggested that the two phenotypes could be allelic. ${ }^{40}$ Molecular analysis of TP63 has not been extensively performed to confirm or disprove this hypothesis. Finally, R Gorlin lists RHS and AEC as a single clinical entity, since only the occurrence of ankyloblepharon filiforme adnatum in the latter distinguishes them. ${ }^{41}$ He clearly states that molecular evidence is awaited to confirm this hypothesis.

This paper describes the mutations found in three Swedish multiplex families: two had EEC, one had RHS. One patient from the RHS family had a slight ankyloblepharon on one eye at birth, and, according to Gorlin's criteria, should be considered affected by AEC. Our work is the first to demonstrate that RHS is due to a TP63 defect and that AEC and RHS are the same clinical entity.

\section{MATERIALS AND METHODS}

Subjects

Families A and C were diagnosed and reported on by GA et al at the Department of Genetics and Pathology, Uppsala University, Sweden, ${ }^{42}$ and family B was diagnosed by BG at the Karolinska Institute, Stockholm, Sweden. Pedigrees are shown in fig 1 and clinical data in table 1 . Informed consent was obtained from all family members before their participation.

Diagnosis of EEC syndrome was obtained following previously described diagnostic criteria. ${ }^{36}$ Both family B and family C included patients with the classic triad. A typical RHS was diagnosed in family A (fig 2) from the combination of ectodermal dysplasia and cleft, absence of ankyloblepharon filiforme adnatum, and hand and nipple anomalies. All three subjects displayed typical facial features, such as narrow or hypoplastic nostrils, maxillary hypoplasia, small mouth, thin lips, small teeth with enamel defects and missing teeth, uncombable dry hair with pili torti, and reduced production of tears and saliva. The mother had a

Figure 1 Pedigrees of the three families.

\begin{tabular}{|c|c|c|c|c|c|}
\hline Family & Patient & Gender & Diagnosis & Clinical signs & Mutation \\
\hline A & $1-2$ & Female & RHS or AEC & C palate, E, slight ankyloblepharon on right eye & 1859 Del A \\
\hline A & $\|-1$ & Female & RHS & E & 1859 Del A \\
\hline A & $\| 1-3$ & Female & RHS & C lip/palate, E & $1859 \mathrm{Del} \mathrm{A}$ \\
\hline B & II-5 & Female & EEC & $\begin{array}{l}\text { Bilateral C lip/palate, left hand S IV/V and absent II/III, right hand } \\
\text { S II/V with absent III/IV and clinodactyly I, both feet S III/IV and absent II }\end{array}$ & $\mathrm{R} 279 \mathrm{C}$ \\
\hline B & III-5 & Male & EEC & $\begin{array}{l}\mathrm{C} \text { lip/palate, obstructed lacrimal ducts, left hand S I/II and absent III, } \\
\text { right hand S I/II, left foot S III/IV and absent II, right foot absent II/III }\end{array}$ & R279C \\
\hline C & $1-2$ & Female & EEC & $\begin{array}{l}\text { Bilateral } C \text { lip/palate, sparse eye lashes and eyebrows, obstructed } \\
\text { lacrimal ducts, bilateral clinodactyly } \mathrm{V} \text {, hypoplastic nails }\end{array}$ & R304Q \\
\hline C & $\| 11$ & Female & EEC & $\begin{array}{l}\text { C lip/palate, hypoplastic nails, sparse hair, obstructed lacrimal ducts, } \\
\text { right hand preaxial polydactyly, left foot postaxial polydactyly, right foot } \\
\text { cutaneous S II/III }\end{array}$ & R304Q \\
\hline C & $\|-2$ & Female & EEC & $\begin{array}{l}\text { Bilateral C, hypoplastic nails, obstructed lacrimal ducts, right hand } \\
\text { short distal phalanges III/IV, preaxial polydactyly, left hand absent distal } \\
\text { phalanges, right foot cutaneous S III/IV, left foot preaxial polydactyly }\end{array}$ & R304Q \\
\hline C & $\| 1-3$ & Male & EEC & $\begin{array}{l}\text { Bilateral C lip/palate, hypoplastic nails, obstructed lacrimal ducts, } \\
\text { right hand cutaneous S } \mathrm{II} / \mathrm{III} \text { and IV/V }\end{array}$ & R304Q \\
\hline C & $\|-4$ & Male & EEC & $\begin{array}{l}\text { Bilateral C lip/palate, hypoplastic nails, obstructed lacrimal ducts, } \\
\text { bilateral hand and foot ectrodactyly, left hand cutaneous SI/II and IV/V, } \\
\text { bilateral foot rudimentary II and III and cutaneous S III/IV }\end{array}$ & R304Q \\
\hline
\end{tabular}

RHS, Rapp-Hodgkin syndrome; AEC, ankyloblepharon-ectodermal dysplasia-cleff; EEC, ectodermal dysplasia, ectrodactyly, cleft lip / palate; E, ectodermal dysplasia (anhidrosis, no tears, sparse hair, pili torti / canaliculi, tooth hypoplasia, dysplastic nails); C, cleff; S, syndactyly. 


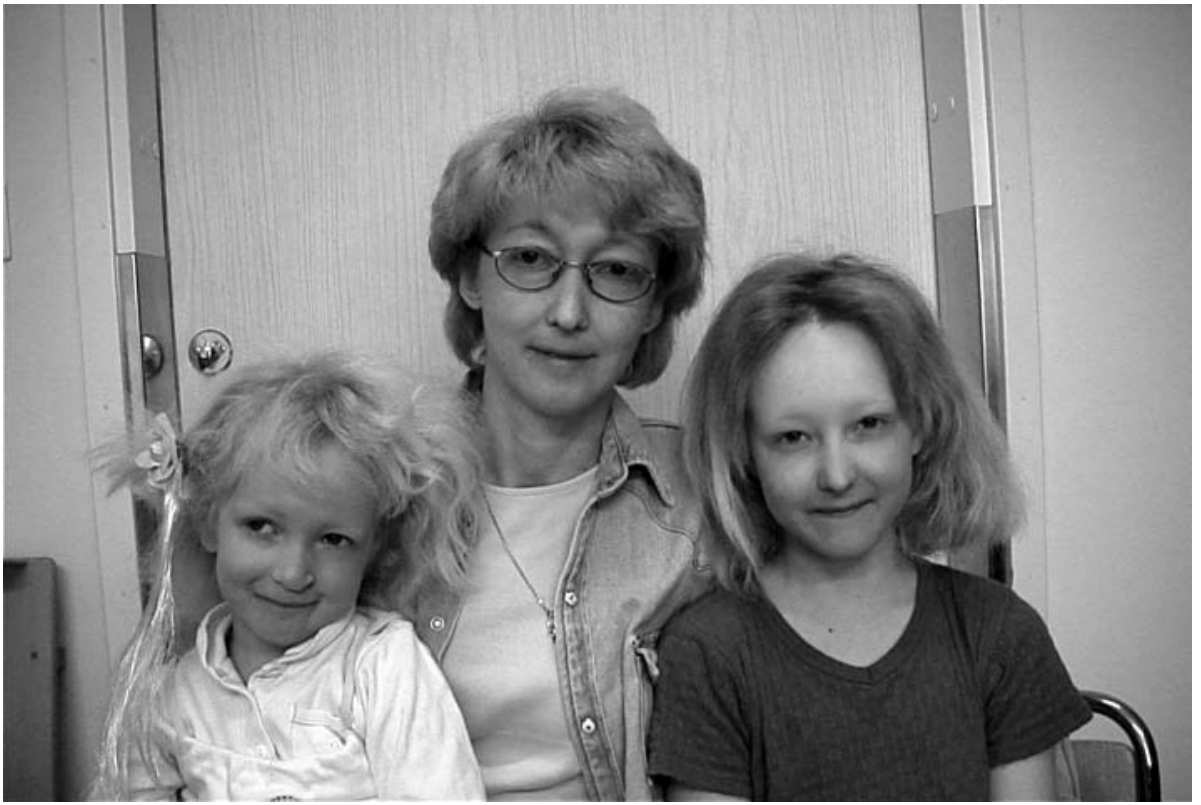

Figure 2 Facial appearance of RHS patients from Family $\mathrm{A}$. The mother is wearing a wig. cleft palate and the younger daughter had a cleft lip and palate. The mother lost her hair after recurrent scalp infections. Both she and her elder daughter had many pigmented naevi. The patients had normal nipples and the mother breastfed her children. The cleft and absence of hand and nipple anomalies excluded LMS in all patients. The absence of ankyloblepharon filiforme excluded AEC, and the patients were diagnosed as affected by RHS. However, a thorough study of the patients' clinical histories ascertained that the mother had a slight ankyloblepharon on the right eye at birth, which was surgically treated. According to Gorlin's criteria, she was affected by AEC.

\section{Segregation and mutational analysis}

Blood samples were drawn from all participants and genomic DNA extracted by standard methods. Segregation of $3 \mathrm{q}$ highly polymorphic markers (D3S3530 and D3S1294) were analysed by PCR amplification followed by acrylamide electrophoresis and silver staining. TP63 genomic screening was performed by PCR amplification of single exons and intron-exon boundaries, followed by sequencing using an ABI PRISM-BigDye Terminator Cycle Sequencing Ready Reaction kit and an ABI PRISM 310 Genetic Analyzer (Applied Biosystems, Warrington, UK). Each exon was sequenced twice using $5^{\prime}$ and $3^{\prime}$-primers (the primer sequence has been reported $)^{24}$; and amino acid position was numbered according to recent literature. ${ }^{14} 43$

Mutation segregation was ascertained by digestion with restriction enzymes. R279C (CGC -> TGC) was identified by PstI, which recognises and cuts the mutant sequence when a mutagenesis primer is used for PCR; R304Q (CGG -> CAG) was recognised by HpaII, which cuts the normal sequence.

\section{RESULTS}

Segregation of 3q highly polymorphic markers (D3S3530 and D3S1294) was concordant with the disease in all three families (data not shown). This suggested that RHS was allelic with EEC. Causal mutations were found: the EEC families carried mutations in the DNA binding domain of p63, namely R279C in exon 7 and R304Q in exon 8, respectively. These mutations are recurrent, since they have been found in several unrelated families. ${ }^{14}$ Full penetrance was always observed, although expression was variable even in the monozygotic twins of family $\mathrm{C}$. This points to a stochastic event in embryo development, since the twins shared the same genetic background. Microsatellite segregation and mutation analysis showed that the mutation was a new event in the paternal meiosis of patient II-5 in family B. Grandparents were not available for the other families.

A

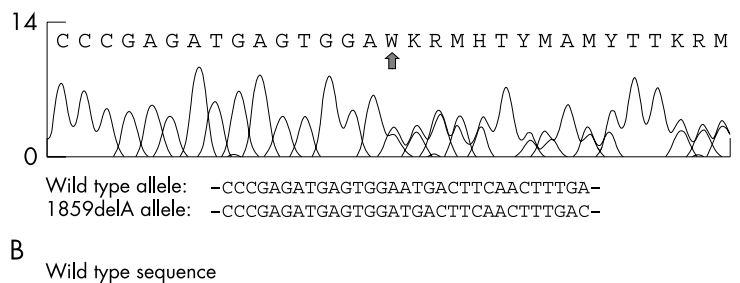

Wild type sequence

IPMMGTHMPMAGDMNGLSPTQALPPPLSMPSTSHCTPPPPYPTDCSIVS | FLARLGCSSCLD YFTTQGLTTIYQIEHYSMD | DLASLKIPEQFHAIWKGILDHRQLHEFSSPSHLLRTPSSAST VSVGSSETRGERVIDAVRFTLRQTISFPPRDEWNDFNFDMDARRNKQQRI KEEGE

1572insA (EEC)

IPMMGTHMPMAGDMNGLSPTQALPPPLSMPSTSHCTPPPPYPTDCSIVS | FLARLGCSSCLD IFHDPGADHHLSD

1576-1577delTT (LMS)

IPMMGTHMPMAGDMNGLSPTQALPPPLSMPSTSHCTPPPPYPTDCS IVS | FLARLGCSSCLD YHDPGADHHLSD

1743-1744de|AA (LMS)

IPMMGTHMPMAGDMNGLSPTQALPPPLSMPSTSHCTPPPPYPTDCSIVS FLARLGCSSCLD YFTTQGLTTIYQIEHYSMD | DLASLKIPEQFRHAIWKGILDHRQLHEFSSPSHLLRTPQCLYS QCGLQ

1742 delC $(A E C)$

IPMMGTHMPMAGDMNGLSPTQALPPPLSMPSTSHCTPPPPYPTDCS IVS | FLARLGCSSCLD YFTTQGLTTIYQIEHYSMD | DLASLKI PEQFRHAIWKG I LDHRQLHEFSSPSHLLRTQAVPL QSVWAPVRPGVSVLLMLCDSPSARPSLSHPEMSGMTSTLTWMLAAISNSASKRRGSEP HHVSSSYPSPNCQPPKSTPA

1859 delA (RHS)

IPMMGTHMPMAGDMNGLSPTQALPPPLSMPSTSHCTPPPPYPTDCSIVS | FLARLGCSSCLD YFTTQGLTTIYQIEHYSMD | DLASLKI PEQFRHAIWKG ILDHRQLHEFSSPSHLLRTPSSAST VSVGSSETRGERVIDAVRFTLRQTISFPPRDEWMTSTLTWMLAAISNSASKRRGSEPHHV SSSYPSPNCQPPKSTPA

Figure 3 (A) Electropherogram from RHS patient II-1. An arrow denotes the DNA change (1859delA). Sequences of the wild type and the mutant alleles are reported. (B)Predicted amino acid sequence resulting from frameshift mutations in the p63 $\alpha$ tail. The vertical bars denote protein portions encoded by exons 12, 13, 14. Bold type indicates the new amino acid sequence resulting from the frameshift. The associated diseases are shown. 
Complete sequencing of DNA from RHS patient II-1 (family A) revealed deletion of an A at position 1859 in exon 14, within codon 620, as illustrated in fig 3(A). Deletion causes a frameshift and affects the $\alpha$ tail.

Exon 14 was subsequently sequenced in all the members of the family. The deletion was found in all three affected members and not in the normal sibling. This new mutation is the most 3' frameshift mutation found so far in TP63.

\section{DISCUSSION}

This paper records the identification of a mutation in TP63 in an RHS family with three affected members; the molecular basis of RHS is thus defined. There has been no previous published demonstration of the molecular basis of RHS, although a recent paper reported analysis of the TP63 gene in a sporadic patient without any mutation being disclosed. ${ }^{34}$ It is possible that there was a causal mutation in the introns and regulatory sequences, which were not screened in that paper.

The mother in family A had a slight ankyloblepharon of one eye at birth. According to Gorlin's criteria, she was affected by AEC rather than RHS. ${ }^{41}$ Thus, our data not only allow classification of RHS among allelic syndromes due to TP63 mutations, but also confirm the hypothesis that AEC and RHS are the same clinical entity.

The 1859delA mutation found in the RHS patients predicts an abnormal $\alpha$ tail. Other $\alpha$ tail mutations have been found in patients with LMS, EEC, AEC, and SHFM, namely: a TT deletion at bases 1576-1577 in exon 13 and a deletion of two As at 1743-1744 in exon 14 in LMS patients; an insertion of an A at base 1572 of exon 13 in an EEC patient; a 1742delC in an AEC patient; and two nonsense mutations (Q634X and E639X) in SHFM patients. ${ }^{14}$ All these mutations affect only the $\alpha$ isoforms of p63, but with different molecular consequences.

The TT deletion in LMS and the A insertion in EEC are both in exon 13. They predict the use of the same frame which reveals a stop codon at base 1611 within exon 13, and an effect on the SAM domain, if expressed. The insA mutant has been expressed in the laboratory and conferred a gain of transactivation. A similar effect was found in a p73 mutant which deleted the $\mathrm{COOH}$ terminus. ${ }^{44}$

The AA deletion in exon 14 in an LMS patient predicts the use of a stop codon at base 1776 .

The delC mutant in exon 14 found in an AEC patient predicts the use of the same frame as that used by the delA mutant in our RHS patients; this predicts a stop codon at base 1991 (TAA), 65 bp downstream to the canonic TGA stop. The two mutant transcripts, however, encode different proteins: delC predicts the addition of 83 amino acids after codon 580, whereas delA predicts the addition of 44 aminoacids after codon 619 , as shown in fig 3(B).

The TID repressive activity mapped to the $\alpha$ tail downstream to the SAM domain ${ }^{14}$ is lost in all the frameshift mutations, including this new mutation. Thus a gain of function is also expected for these mutants, if they are indeed expressed. It is intriguing that the use of the same frame by different mutations is responsible for similar phenotypes: insA and delTT for EEC and LMS, and delC and delA for AEC and RHS, respectively.

Recently, an unusual mutation affecting ex 11 splicing was found in an AEC patient, IVS10-2 ${ }^{45}$ : the skipping of exon 11 results in a frameshift. The molecular consequences are different from those expected from the $\alpha$ tail frameshifts, because not only the $\alpha$ but also the $\beta$ isoforms are affected by IVS10-2.

Our data show that RHS is due to a defect in TP63. Thus, the spectrum of malformative diseases due to TP63 abnormalities is further extended. ${ }^{14}{ }^{28}$ We also show that RHS and
AEC are probably the same clinical entity. Further studies are needed to elucidate the developmental pathways that involve the different functions of p63 isotypes. These may clarify the pathogenesis of diseases due to TP63 mutations and their apparent genotype-phenotype correlation.

\section{ACKNOWLEDGEMENTS}

We wish to thank Dr M Silengo for helpful discussion.

\section{ELECTRONIC DATABASE INFORMATION}

Accession numbers and the URL for data in this article are as follows: Online Mendelian Inheritance in Man (OMIM), http://www.ncbi.nlm. nih.gov/Omim/ for EEC (MIM 604292), for SHFM (MIM 183600), for AEC (MIM 106260), for LM (MIM 603543), for ADULT (MIM 103285), and for RHS (MIM 129400).

\section{Authors' affiliations \\ I Dianzani, Department of Medical Sciences, Università del Piemonte Orientale, Novara, Italy \\ E Garelli, A Carando, Department of Pediatric Sciences, Università Torino, Italy \\ B Gustafsson, Karolinska Institute, Stockholm, Sweden \\ P Gustavsson, N Dahl, G Annerén, Department of Genetics and Pathology, Uppsala University, Sweden}

This work was partially supported by Telethon Grant E619 and by MURST grants to ID. AC is supported by a Banca di Credito del Piemonte fellowship.

Correspondence to: Prof. I Dianzani, Department of Medical Sciences, Università del Piemonte Orientale, Via Solaroli 17, 28100 Novara, Italy; irma.dianzani@med.unipmn.it

Revised version received 2003

Accepted for publication 21 May 2003

\section{REFERENCES}

1 Yang A, Kaghad M, Wang Y, et al. P63, a p53 homolog at 3q27-29, encodes multiple products with transactivating, death-inducing, and dominant-negative activities. Mol Cell 1998;2:305-316.

2 Yang A, McKeon F. P63 and p73: p53 mimics, menaces and more. Nat Rev 2000; 1:199-207.

3 lkawa S, Nakagawara A, Ikawa Y. P53 family genes: structural comparison, expression and mutation. Cell Death Differ 1999;6:1 154-61.

4 Irwin MS, Kaelin WG. P53 family update: p73 and p63 develop their own identities. Cell Growth and Differentiation 2001;12:337-49.

5 Kaelin WG. The p63 gene family. Oncogene 1999;18:7701-5.

6 Mills AA, Zheng B, Wang XJ, et al. P63 is a p53 homologue required for limb and epidermal morphogenesis. Nature 1999;398:708-13.

7 Marin MC, Kaelin W. P63 and p73: old members of a new family. Biochem Biophys Acta 2000;1470:M93-M100.

8 Levrero M, De Laurenzi V, Costanzo A, et al. The p53/p63/p73 family of transcription factors: overlapping and distinct functions. J Cell Sc 2000:113:1661-70

9 Jost C, Marin M, Kaelin WJ. P73 is a human p53-related protein that induces apoptosis. Nature 1997;389:191-4.

10 De Laurenzi VD, Costanzo A, Barcaroli D, et al. Two new splice variants, gamma and delta, with different transcriptional activity. J Exp Med 1998; 188:1763-8.

11 De Laurenzi VD, Catani MV, Terrinoni A, et al. Additional complexity in p73, induction by mitogens in lymphoid cells and identification of two new splicing variants $\epsilon$ and $\zeta$. Cell Death Differ 1999;6:389-90.

12 Ueda $Y$, Hiiikata M, Takagi S, et al. New p73 variants with altered C-terminal structures have varied transcriptional activities. Oncogene 1999;18:4993-8.

13 Agami R, Blandino G, Oren M, et al. Interaction of c-abl and p73 $\alpha$ and their collaboration to induce apoptosis. Nature 1999;399:809-13.

14 Van Bokhoven H, Brunner HG. Splitting p63. Am J Hum Genet 2002;71:1-13.

15 Chi SW, Ayed A, Arrowsmith CH. Solution structure of a conserved C-terminal domain of 773 with structural homology to the SAM domain. EMBO J 1999; 18:4438-45.

16 Thanos CD, Bowie JU. P53 family members p63 and p73 are SAM domaincontaining proteins. Protein Sci 1999;8:1708-10.

17 Ghioni P, Bolognese F, Dujif PHG, et al. Complex transcriptional effects of p63 isoforms: identification of novel activation and repression domains. Mol Cell Biol 2002;22:8659-68.

18 Di Como CJ, Urist MJ, Babayan I, et al. P63 expression profiles in human normal and tumor tissue. Clin Cancer Res 2002;8:494-501.

19 Irwin MS, Kaelin WG. Role of the newer p53 family members in malignancy. Apoptosis 2001;6:17-29.

20 Celli J, Duiff $\mathrm{P}$, Hamel $\mathrm{BCJ}$, et al. Heterozygous germline mutations in the p53 homolog p63 are the cause of EEC syndrome. Cell 1999;99:143-53. 
21 lanakiev $\mathbf{P}$, Kilpatrick MW, Toudjarska I et al Split-hand/split-foot malformation is caused by mutations in the $\mathrm{p} 63$ gene on $3 q 27$. Am J Hum Genet 2000;67:59-66

22 Wessagowit V, Mellerio JE, Pembroket AC et al. Heterozygous germline missense mutation in the $\mathrm{p} 63$ gene underlying EEC syndrome. Clin Exp Dermatol 2000;25:441-3.

23 McGrath JA, Duijf PHG, Doetsch V, et al. Hay-Wells syndrome is caused by heterozygous missense mutations in the SAM domain of p63. Hum Mol Genet $2001 ; 10: 221-9$

24 Van Bokhoven H, Hamel BCJ, Bamshad M, et al. p63 gene mutation in EEC syndrome, limb-mammary syndrome, and isolated split hand- split foot malformation suggest a genotype-phenotype correlation. Am J Hum Genet 2001;69:481-92

25 Kosaki R, Ohashi H, Yoshihashi H, et al. A de novo mutation (R279C) in the p63 gene in a patient with EEC syndrome. Clin Genet 2001;60:314-15.

26 Amiel J, Bougeard G. Francannet C, et al. TP63 mutation in ADULT syndrome. Eur J Hum Genet 2001;9:642-5.

27 Dujif PHG, Kaate R, Vanmolkot KRJ, et al. Gain of function mutation in ADULT syndrome reveals the presence of a second transactivation domain in p63. Am J Hum Genet 2002;69:481-92.

28 Brunner HG, Hamel BC, Van Bokhoven H. The p63 gene in EEC and other syndromes. J Med Genet 2002;39:377-81.

29 Silengo MC, Davi GF, Bianco R, et al. Distinctive hair changes (pili torti) in Rapp-Hodgkin ectodermal dysplasia syndrome. Clin Genet 1982;21:297-300.

30 Salinas CF, Montes GM. Rapp-Hodgkin syndrome: observations on ten cases and characteristic hair changes (pili canaliculi). Birth Defects Orig Art Ser 1988;24:149-68.

31 Cliff S, Holden CA. What syndrome is this? Rapp-Hodgkin syndrome. Pediatr Dermatol 1997; 14:149-50.

32 Hicks J, Metry DW, Barrish J, et al. Uncombable hair (cheveux incoiffables, pili trianguli et canaliculi) syndrome: brief review and role of scanning electron microscopy in diagnosis. Ultrastruct Pathol 2001;25:99-103.
33 Kantaputra PN, Pruksachatkunakorn C, Vanittanakom P. Rapp-Hodgkin syndrome with palmoplantar keratoderma, glossy tongue, congenital absence of lingual frenum and of sublingual caruncles: newly recognized findings. Am J Med Genet 1998;79:343-6.

34 Neilson DE, Brunger JW, Heeger S, et al. Mixed clefting type in RappHodgkin syndrome. Am J Med Genet 2002;108:281-4.

35 Rapp RS, Hodgkin WE. Anhidrotic ectodermal dysplasia: autosomaldominant inheritance with palate and lip abnormalities. J Med Genet 1968;5:269-72.

36 Roelfsema NM, Cobben JM. The EEC syndrome: a literature study. Clin Dysmorphol 1996;5:115-27.

37 Wannarachue N, Hall BD, Smith DW. Ectodermal dysplasia and multiple defects (Rapp-Hodgkin type). J Pediatr 1972;81:1217-18.

38 Fryns JP, Legius E, Dereymaeker AM, et al. EEC syndrome without ectrodactyly: report of two new families. J Med Genet 1990;27:165-8.

39 Kuster W, Majewski F, Meinecke P. EEC syndrome without ectrodactyly? Report of 8 cases. Clin Genet 1985;28:130-5

40 Moerman P, Fryns J-P. Ectodermal dysplasia, Rapp-Hodgkin type in a mother and severe ectrodactyly-ectodermal dysplasia-clefting syndrome (EEC) in her child. Am J Med Genet 1996;63:479-81.

41 Gorlin RJ, Cohen MM, Hennekam RCM. Syndromes of the head and neck. 4th edn. Oxford, UK: Oxford University Press, 2001:883-86.

42 Annerén G Andersson T, Lindgren PG, et al. Ectrodactyly-ectodermal dysplasia-clefting syndrome (EEC): the clinical variation and prenatal diagnosis. Clin Genet 1991;40:257-62.

43 van Bokhoven H, Brunner HG. Splitting p63. Am J Hum Genet 2003;72:779

44 Ozaki T, Naka M, Takada $\mathrm{N}$, et al. Deletion of the $\mathrm{COOH}$-terminal region of p73 $\alpha$ enhances both its transactivation function and DNA-binding activity but inhibits induction of apoptosis in mammalian cells. Cancer Res 1999:59:5902-7.

45 Barrow LL, Van Bokhoven H, Daak-Hirsch S, et al. Analysis of the p63 gene in classical EEC syndrome, related syndromes, and non-syndromic orofacia clefts. J Med Genet 2002;39:559-66. 